\title{
The Crystal Structure of $\mathrm{Hg}_{2} \mathrm{O}_{2} \mathrm{NaI}$ Studied by X-Ray and Neutron Diffraction Methods
}

\author{
KARIN A URIVILLIUS \\ Institute of Inorganic and Physical Chemistry, University of Stockholm, Stockholm, Sueden; \\ Joint Establishment for Nuclear Energy Research, Kjeller, Norway
}

\begin{abstract}
The crystal structure of $\mathrm{Hg}_{2} \mathrm{O}_{2} \mathrm{NaI}$ has been studied by X-ray (single crystal) and neutron (powder) diffraction methods. The crystals are hexagonal (space group $P 6_{2} 22(P 6,22)$ ) with the cell edges $a=$ 6.667 $\AA$ and $c=10.054 \AA$. The unit cell contains three formula units. The mercury and oxygen/atoms form infinite planar chains, -Hg-O-Hg-O-, lying perpendicularly to the $c$ axis of the unit cell. The $\mathrm{Hg}-\mathrm{O}$ distance is $2.03 \AA$ and the angles $\mathrm{O} \cdot \mathrm{Hg}-\mathrm{O}$ and $\mathrm{Hg}-\mathrm{O}-\mathrm{Hg}$ are $180^{\circ}$ and $110^{\circ}$, respectively.
\end{abstract}

\begin{abstract}
A s earlier reported ${ }^{1,2}$, the structures of the orthorhombic and hexagonal

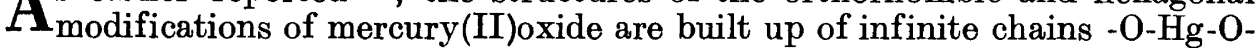
which, in the orthorhombic modification, are of planar zig-zag type and, in the hexagonal modification, of spiral type. Every mercury atom is thus coordinated to two oxygen atoms and every oxygen atom to two mercury atoms. The aim of the present investigation was to find whether such chains -O-Hg-O- are fundamental constituents of other mercury(II)salts containing oxygen and whether this arrangement is independent of the other kinds of atoms occurring in the structure.
\end{abstract}

\section{PREPARATION AND ANALYSIS}

In connection with the preparation of the hexagonal modification of mercury(II)oxide, the complex compound $\mathrm{Hg}_{2} \mathrm{O}_{2} \mathrm{NaI}$, earlier reported by Laruelle ${ }^{3}$, was synthesized. The best way for preparing $\mathrm{Hg}_{2} \mathrm{O}_{2} \mathrm{NaI}$ is to mix one part of a cold solution of $0.1 \mathrm{M} \mathrm{K}_{2} \mathrm{HgI}_{4}$ containing an excess of $\mathrm{KI}$ with two parts of $10 \mathrm{M} \mathrm{NaOH}$ at about $0^{\circ} \mathrm{C}$ and to keep the solution at this temperature for about $100 \mathrm{~h}$. The temperature was then slowly increased to room temperature and the substance obtained, which consisted of beautiful yellow pencil-shaped crystals, was then filtered off. Another way of preparing this compound is to heat equivalent quantities of mercury(II)oxide and sodium 
iodide in a fused glass tube to $130^{\circ} \mathrm{C}$ for about $100 \mathrm{~h}$. This method, however, did not give a pure sample.

Attempts were made to replace the sodium atoms in the compound with lithium, potassium, rubidium and caesium. However, these efforts have not yet been successful.

The compound $\mathrm{Hg}_{2} \mathrm{O}_{2} \mathrm{NaI}$ decomposes into orthorhombic $\mathrm{HgO}$ and $\mathrm{NaI}$ when heated in open air to higher temperatures. Thus, a powder diagram of the residue, after the substance had been heated to $200^{\circ} \mathrm{C}$ for 14 days, did not show any lines characteristic for $\mathrm{Hg}_{2} \mathrm{O}_{2} \mathrm{NaI}$.

The compound is not stable if treated with water - it decomposes into other, not yet identified, phases. Upon exposure to light, the yellow crystals of the substance become dark green. To investigate this phenomenon more closely, a sample of $\mathrm{Hg}_{2} \mathrm{O}_{2} \mathrm{NaI}$ was exposed to U.V. light for a long time. X-Ray diagrams of the green substance showed only lines characteristic for $\mathrm{Hg}_{2} \mathrm{O}_{2} \mathrm{NaI}$. A microscopic examination revealed, however, the presence of small drops of mercury.

The pure sample was analysed for $\mathrm{Hg}, \mathrm{Na}, \mathrm{K}, \mathrm{I}$ and $\mathrm{H}_{2} \mathrm{O}$ and was found to contain neither potassium nor water. The mercury analysis was performed using electrolysis ${ }^{4}$, the sodium and potassium analyses flame spectrophotometrically using a Beckman D.U. spectrophotometer ${ }^{5}$ and the iodine analysis by iodometric titration ${ }^{6}$ after the sample had been brought into solution by melting with sodium hydroxide in a gold crucible. The water analysis was performed according to Penfield ?. The results of the analyses are in fair agreement with the values calculated for $\mathrm{Hg}_{2} \mathrm{O}_{2} \mathrm{NaI}$ (Found \%: $\mathrm{Hg}$ 67.9; $\mathrm{Na} 3.8$; I 20.9. Calc. $\mathrm{Hg} 68.8 ; \mathrm{Na} 3.9 ; \mathrm{I} 21.8$ ).

\section{CELL DIMENSIONS AND SYMMETRY}

The powder photographs were taken in a Guinier focusing camera of 80 $\mathrm{mm}$ diameter using $\mathrm{Cu} K \alpha_{1}$ radiation and potassium chloride $\left(a=6.2930 \AA^{(8)}\right)$ as an internal standard. The powder pattern is given in Table 1. Heavily exposed photographs did not show any lines that were not visible in normally exposed ones. The powder pattern could be interpreted by means of a hexagonal unit cell with the following cell dimensions:

$$
a=6.667 \AA \quad c=10.054 \AA \quad V=387.0 \AA^{3}
$$

The observed density, $7.0 \mathrm{gcm}^{-3}$, indicates a cell content of three formula units $\mathrm{Hg}_{2} \mathrm{O}_{2} \mathrm{NaI}$ (calculated density $7.5 \mathrm{gcm}^{-3}$ ). For the single crystal photographs, $\mathrm{Cu} K$ and $\mathrm{Mo} K$ radiations were used. Rotation diagrams were taken around the $a$ and $c$ axes and Weissenberg photographs were used to register the reflexions $h 0 l-h 3 l$ and $h k 0-h k 5$.

Since $|F(h k 0)|^{2}$ was found throughout to be equal to $|F(h k 3)|^{2}, \mid\left(\left.F(h k 1)\right|^{2}\right.$ equal to $|\boldsymbol{F}(h k 4)|^{2}$ and $|\boldsymbol{F}(h k 2)|^{2}$ equal to $|\boldsymbol{F}(h k 5)|^{2}$ within the limits of experimental error, the heavy atoms of the structure must be situated at the planes normal to the $c$ axis of the unit cell at the $z$ values 0 and $\pm \frac{1}{3}$ or $\frac{1}{2}$ and $\pm \frac{1}{6}$. The coefficients

$$
\sum_{l=-\infty}^{l=+\infty}|F(h k l)|^{2}
$$

were thus approximated by the expressions

Acta Chem. Scand. 14 (1960) No. 10 
Table 1. Powder diagram (Guinier focusing camera) and powder diffractogram (Geiger Mueller diffractometer) of $\mathrm{Hg}_{2} \mathrm{O}_{2} \mathrm{NaI}$. $I_{\text {calc }}$ is normalized so as to give the best agreement with $I_{\text {obs. }}$

\begin{tabular}{|c|c|c|c|c|c|c|}
\hline$h k l$ & $\begin{array}{c}10^{4} \sin ^{2} \Theta_{\mathrm{obs}} \\
\text { Guinier }\end{array}$ & $10^{4} \sin ^{2} \Theta_{\mathrm{calc}}$ & $\underset{\text { Guinier }}{I_{\text {obs }}}$ & $\underset{\text { Guinier }}{I_{\text {calc }}^{*}}$ & $\begin{array}{c}I_{\text {obs }} \\
\text { Diffr. }\end{array}$ & $\underset{\substack{I_{\text {calc }}^{* *} \\
\text { Diffr }}}{ }$ \\
\hline 100 & 178 & 178 & st & 540 & 218 & 236 \\
\hline 101 & 237 & 237 & $\mathrm{~m}$ & 165 & 52 & 9 \\
\hline 102 & 413 & 413 & $\mathbf{w}$ & 105 & 35 & 31 \\
\hline 003 & 529 & 528 & vst & 1072 & 376 & 415 \\
\hline 110 & 534 & 534 & $\mathbf{m}$ & 276 & & \\
\hline 111 & - & 593 & - & 11 & - & 0 \\
\hline 103 & 707 & 706 & $\mathbf{m}$ & 518 & 909 & 824 \\
\hline 200 & 713 & 712 & vst & 2009 & & \\
\hline 112 & 769 & 769 & vvw & 8 & - & 3 \\
\hline 201 & - & 771 & 一 & 0 & & \\
\hline 202 & - & 947 & - & 0 & - & O \\
\hline 113 & 1062 & 1062 & $\mathrm{~m}$ & 360 & 149 & 112 \\
\hline 104 & - & 1117 & - & 26 & - & 8 \\
\hline 203 & 1240 & 1240 & vst & 1587 & 5669 & 530 \\
\hline 210 & 1245 & 1246 & $\mathbf{m}$ & 158 & & \\
\hline 211 & 1304 & 1305 & $\mathbf{w}$ & 47 & - & 14 \\
\hline 114 & - & 1473 & - & 5 & - & 13 \\
\hline 212 & 1480 & 1481 & $w$ & 41 & & \\
\hline $\begin{array}{lll}3 & 0 & 0\end{array}$ & 1601 & 1602 & $\mathbf{w}$ & 65 & 20 & 18 \\
\hline $\left.\begin{array}{llll}1 & 0 & 5 \\
2 & 0 & 4\end{array}\right\}$ & 1648 & 1645 & drw & 17) & & \\
\hline $\begin{array}{llll}2 & 0 & 4 \\
3 & 0 & 1\end{array}$ & - & $\begin{array}{l}1651 \\
1660\end{array}$ & \}$^{v w}$ & $0\}$ & - & 6 \\
\hline $\begin{array}{lll}3 & 0 & 1 \\
2 & 1 & 3\end{array}$ & 1774 & $\begin{array}{l}1060 \\
1774\end{array}$ & st & 346 & 100 & 93 \\
\hline $\begin{array}{lll}3 & 0 & 2\end{array}$ & - & 1837 & - & 5 & 100 & 93 \\
\hline 115 & - & 2001 & - & 4 & - & 1 \\
\hline 006 & 2112 & 2113 & $\mathrm{~m}$ & 196 & & \\
\hline $\begin{array}{llll}3 & 0 & 3\end{array}$ & - & 2130 & - & 147 & 258 & 227 \\
\hline 220 & 2136 & 2136 & $\mathrm{~m}$ & 553 & & \\
\hline 205 & - & 2179 & - & $0)$ & & \\
\hline 214 & - & 2185 & - & $25\}$ & - & 6 \\
\hline 221 & - & 2194 & - & 0) & & \\
\hline 106 & 2291 & 2291 & $\mathrm{w}$ & 63) & 34 & 32 \\
\hline $\begin{array}{lll}3 & 1 & 0\end{array}$ & 2313 & 2314 & $\mathbf{w}$ & $64\}$ & & \\
\hline $\left.\begin{array}{lll}2 & 2 & 2 \\
3 & 1 & 1\end{array}\right\}$ & 2370 & $\begin{array}{l}2370 \\
2372\end{array}$ & ovw & $\begin{array}{r}0 \\
20\end{array}$ & - & 0 \\
\hline $\left.\begin{array}{lll}3 & 0 & 4 \\
3 & & 9\end{array}\right\}$ & 2544 & 2541 & Vvw & 3) & - & 1 \\
\hline $\left.\begin{array}{lll}3 & 1 & 2 \\
1 & 1 & 6\end{array}\right\}$ & - & $\begin{array}{l}2548 \\
2647\end{array}$ & S & $\begin{array}{l}20\} \\
713\end{array}$ & 188 & 178 \\
\hline 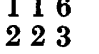 & 2663 & $\begin{array}{l}2647 \\
2664\end{array}$ & $\overline{s t}$ & $\left.\begin{array}{r}71 \\
748\end{array}\right\}$ & 188 & \\
\hline 215 & - & 2713 & - & 19 & - & 4 \\
\hline 206 & 2825 & 2825 & st & 759 & & \\
\hline 313 & - & 2842 & - & 196 & 275 & 269 \\
\hline 400 & 2847 & 2848 & st & 426) & & \\
\hline 401 & - & 2906 & - & 0) & & \\
\hline 107 & - & 3054 & - & 8 & & \\
\hline 305 & - & 3069 & - & $3\}$ & - & - \\
\hline 224 & - & 3075 & - & 0 & & \\
\hline 402 & - & 3082 & - & 0) & & \\
\hline 314 & - & 3253 & - & $16^{\prime}$ & - & 3 \\
\hline 216 & - & 3359 & - & 109 ) & & \\
\hline $\begin{array}{lll}4 & 03 \\
3 & 9 & 0\end{array}$ & $\begin{array}{r}3377 \\
-\end{array}$ & 3376 & st & $\left.\begin{array}{r}575 \\
45\end{array}\right\}$ & 120 & 125 \\
\hline 320 & - & 3381 & - & 45) & & \\
\hline
\end{tabular}




\begin{tabular}{|c|c|c|c|c|c|c|}
\hline$h k l$ & $\begin{array}{c}10^{4} \sin ^{2} \Theta_{\text {obs }} \\
\text { Guinier }\end{array}$ & $10^{4} \sin ^{2} \Theta_{\text {calc }}$ & $\begin{array}{c}I_{\text {obs }} \\
\text { Guinier }\end{array}$ & $\underset{\text { Guinier }}{I_{\text {calc }}^{*}}$ & $\begin{array}{l}I_{\text {obs }} \\
\text { Diffr. }\end{array}$ & $\begin{array}{l}I_{\text {calc }}^{* *} \\
\text { Diffr }\end{array}$ \\
\hline $\begin{array}{lll}1 & 1 & 7 \\
3 & 2 & 1\end{array}$ & $=$ & $\begin{array}{l}3410 \\
3440\end{array}$ & - & $\begin{array}{r}3 \\
14\end{array}$ & - & 3 \\
\hline 207 & - & 3588 & 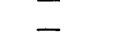 & 0 & & \\
\hline 225 & - & 3603 & - & $0\}$ & - & 2 \\
\hline 322 & - & 3616 & - & 14) & & \\
\hline 306 & 3713 & 3715 & vvw & 61) & - & 18 \\
\hline 410 & 3737 & 3737 & vow & $60\}$ & & \\
\hline 315 & - & 3781 & - & $16\}$ & & \\
\hline 404 & - & 3787 & - & $0\}$ & - & 3 \\
\hline 411 & - & 3796 & - & 7) & & \\
\hline 323 & 3911 & 3910 & $\mathrm{~m}^{-}$ & $160)$ & & \\
\hline 108 & - & 3935 & - & 8 & 8 & 24 \\
\hline 412 & - & 3972 & - & 7) & & \\
\hline 217 & - & 4122 & - & 19 & - & - \\
\hline 226 & 4249 & 4249 & st & 844 & & \\
\hline 413 & 4268 & 4266 & $\mathrm{~m}$ & $215\}$ & 89 & 116 \\
\hline 118 & - & 4291 & - & 4) & & \\
\hline 405 & - & 4315 & - & $0)$ & - & 2 \\
\hline 324 & - & 4321 & - & $16\}$ & & \\
\hline 316 & 4426 & 4427 & $w$ & 119 & - & 12 \\
\hline
\end{tabular}

$$
\begin{aligned}
& I_{\text {calc }}^{*}=10^{-4} p \varphi(\Theta) F^{2} ; \quad \varphi(\Theta)=\frac{1+\cos 2 \alpha \cos ^{2} 2 \Theta}{\sin \Theta(1+\cos 2 \alpha) \cos ^{2}(2 \Theta-\beta) \sin 2 \Theta} \\
& I_{\text {calc }}^{* *}=10^{-4} p \frac{1+\cos ^{2} \Theta}{\sin ^{2} \Theta \cos \Theta} F^{2}
\end{aligned}
$$

(cf. Ref. 9).

$$
|F(h k 0)|^{2}+|F(h k 3)|^{2}+|F(h k 1)|^{2}+|F(h k 4)|^{2}+|F(h k 2)|^{2}+|F(h k 5)|^{2} .
$$

The Laue symmetry found from the Weissenberg photographs was $6 / \mathrm{mmm}$. In the powder and Weissenberg photographs, the following spectra were systematically missing: $h=0, k=0, l \neq 3 n$ and $h, k$ even, $l \neq 3 n$ ( $n$ is an integer). This is characteristic for the enantiomorphous space groups 10 $P_{6} 22$ (No. 180 ) and $P 6_{4} 22$ (No. 181). Possible space groups are: $P 6 / \mathrm{mmm}$ (No. 191), $P \overline{6} 2 m$ (No. 189), $P \overline{6} m 2$ (No. 187), $P 6 \mathrm{~mm}$ (No. 183) and $P 622$ (No. 177).
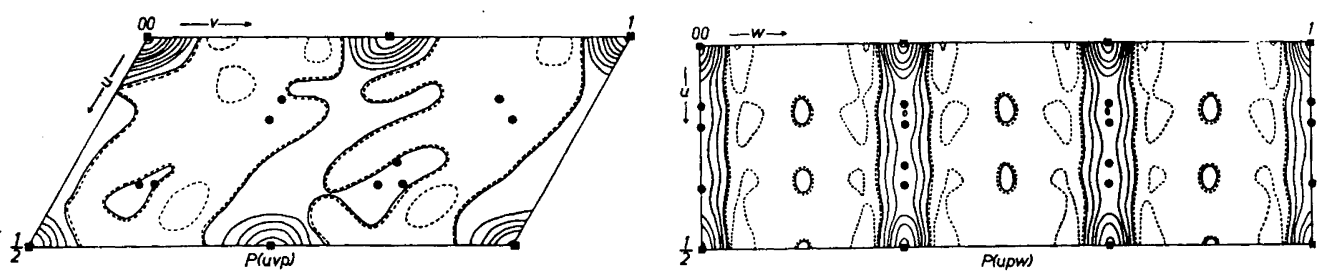

Fig. 1. The Patterson functions $P(u v p)$ and $P(u p w)$. The vectors $\mathrm{Hg}-\mathrm{Hg}(\square)$, Hg-I $(\Delta)$ and $\mathrm{Hg}-\mathrm{O}(O)$ for the final structure are indicated. Dashed lines indicate negative values. 


\section{THE POSITIONS OF THE MERCURY ATOMS}

To locate the heavy metal atoms in the unit cell, the Patterson projections $P(u v p)$ and $P(u p w)$ (Fig. 1) were calculated using $F^{2}$ values derived from the visually estimated intensities of the Weissenberg photographs.

Now in space group $P 6_{6} 22$ (No. 180) and analogously for the enantiomorphous space group $\mathrm{P}_{4} 22$ (No. 181 ), it is possible for the six mercury atoms to occupy one of the sixfold point positions $6(j), 6(i), 6(h), 6(g), 6(f)$ and $6(e)$ or a combination of two threefold point positions $3(d), 3(c), 3(b)$ and $3(a)$. Since it is not possible to distinguish between the two characteristic space groups, one of them, viz. $P 6_{2} 22$, is chosen arbitrarily.

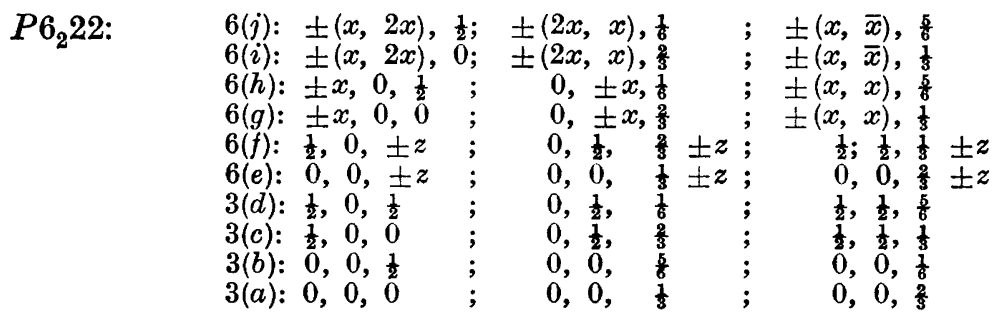

The possible combinations of the threefold point positions are:

$3(a)+3(b) ; 3(a)+3(c) ; 3(a)+3(d) ; 3(b)+3(c) ; 3(b)+3(d)$ ? and $3(c)+3(d)$.

On displacing the origin of the unit cell by $\frac{c}{2}$, however, the point position $6(j)$ becomes identical to $6(i), 6(h)$ to $6(g), 3(a)+3(b)$ to $3(c)+3(d), 3(a)+$ $3(c)$ to $3(b)+3(d)$ and $3(a)+3(d)$ to $3(b)+3(c)$.

The $\mathrm{Hg}-\mathrm{Hg}$ vectors $u, v, w$, required by these possibilities are given in Table 2. This table should be compared with Fig. 1.

The major maxima of the two Patterson projections should be mainly due to mercury-mercury vectors. The point positions $6(e)$ and $3(a)+3(d)$ cannot explain the high maxima at

$u=\frac{1}{2}, v=0 ; u=0, v=\frac{1}{2}$ and $u=\frac{1}{2}, v=\frac{1}{2}$ in $P(u v p)$ and can thus be excluded. Since there do not exist any heavy maxima at $u=\frac{1}{2}, v=\frac{1}{6}$ or $u=0, v=\frac{1}{6}$ in $P(u v p)$, the combination $3(a)+3(b)$ can also be ruled out. Nor was it possible to find an $x$ parameter for the vectors $u, v, w$, of the point positions $6(j)$ and $6(h)$ which could satisfy the Patterson projections $P(u v p)$ and $P(u p w)$. Thus the remaining possibilities for the positions of the six mercury atoms in $P 6_{2} 22$ (No. 180) are: $6(f)$ with $z=0.333$ or $3(a)+3(c)$. By calculating the values of the structure factors $\left|F_{h k l}\right|=\sqrt{\mathrm{A}^{2}+\mathrm{B}^{2}}$ for the two geometrically different arrangements of the six mercury atoms, it was found that they gave the same values. Thus, by evaluating the Patterson projections $P(u v p)$ and $P(u p w)$ above, a homometric pair of arrangements for the mercury atoms was found. These two homometric mercury atom positions gave rise to six possible point positions for the three iodine atoms. The Patterson projections $P(u v p)$ and $P(u p w)$ were then examined for these different possibilities. 
Table 2. Required vectors $\mathrm{Hg}-\mathrm{Hg}$ in the Patterson functions.

\begin{tabular}{|c|c|c|c|c|c|}
\hline \multirow[t]{2}{*}{$6(j):$} & $u$ & & $v$ & $w$ & Relative $\nabla$ \\
\hline & $\begin{array}{l} \pm(3 x \\
\pm(x) \\
0 \\
\pm 3 x \\
\pm(2 x \\
\pm(x \\
\pm(4 x \\
\pm(2 x \\
\pm(2 x\end{array}$ & , & $\begin{array}{c}3 x) \\
\bar{x} \\
\pm 3 x \\
0 \\
x) \\
2 x) \\
2 x) \\
4 x) \\
2 \bar{x})\end{array}$ & $\begin{array}{r} \pm \frac{1}{3} \\
\pm \frac{1}{3} \\
\pm \frac{1}{3} \\
\pm \frac{1}{3} \\
\pm \frac{1}{3} \\
\pm \frac{1}{3} \\
0 \\
0 \\
0\end{array}$ & $\begin{array}{l}4 \\
4 \\
4 \\
4 \\
4 \\
4 \\
2 \\
2 \\
2\end{array}$ \\
\hline 6(h): & $\begin{array}{l} \pm(x \\
\pm(x \\
\pm(x \\
\pm(2 x \\
0 \\
\pm \quad x \\
\pm 2 x \\
\pm 0 \\
\pm(2 x\end{array}$ & , & $\begin{array}{c}\bar{x} \\
x \\
2 x \\
x \\
\pm x \\
\pm 0 \\
0 \\
\pm 2 x \\
\pm 2 x)\end{array}$ & $\begin{array}{r} \pm \frac{1}{3} \\
\pm \frac{1}{3} \\
\pm \frac{1}{3} \\
\pm \frac{1}{8} \\
\pm \frac{1}{8} \\
\pm \frac{1}{8} \\
0 \\
0 \\
0\end{array}$ & $\begin{array}{l}4 \\
4 \\
4 \\
4 \\
4 \\
4 \\
2 \\
2 \\
2\end{array}$ \\
\hline $6(f):$ & $\begin{array}{l}\frac{1}{2} \\
0 \\
\frac{1}{2} \\
0 \\
\frac{1}{2} \\
0 \\
\frac{1}{2}\end{array}$ & & $\begin{array}{l}0 \\
\frac{1}{2} \\
\frac{1}{2} \\
0 \\
0 \\
\frac{1}{2} \\
\frac{1}{2}\end{array}$ & $\begin{array}{l} \pm \frac{1}{3} \\
\pm \frac{1}{3} \\
\pm \frac{1}{3} \\
\pm 2 z \\
\pm\left(2 z \pm \frac{1}{3}\right) \\
\pm\left(2 z \pm \frac{1}{3}\right) \\
\pm 2\left(z \pm \frac{1}{3}\right)\end{array}$ & $\begin{array}{l}\mathbf{4} \\
\mathbf{4} \\
\mathbf{4} \\
\mathbf{6} \\
\mathbf{4} \\
\mathbf{4} \\
\mathbf{4}\end{array}$ \\
\hline 6(e): & $\begin{array}{l}0 \\
0 \\
0 \\
0\end{array}$ & & $\begin{array}{l}0 \\
0 \\
0 \\
0\end{array}$ & $\begin{array}{l} \pm \frac{1}{3} \\
\pm 2 z \\
\pm\left(2 z \pm \frac{1}{3}\right) \\
\pm\left(2 z \pm \frac{2}{3}\right)\end{array}$ & $\begin{array}{r}12 \\
6 \\
8\end{array}$ \\
\hline $3(a)+3(b):$ & $\begin{array}{l}\frac{1}{2} \\
\frac{1}{2} \\
0 \\
0 \\
\frac{1}{2} \\
\frac{1}{2}\end{array}$ & & $\begin{array}{l}0 \\
0 \\
\frac{1}{2} \\
\frac{1}{2} \\
\frac{1}{2} \\
\frac{1}{2}\end{array}$ & $\begin{array}{l} \pm \frac{1}{6} \\
\pm \frac{1}{3} \\
\pm \frac{1}{6} \\
\pm \frac{1}{3} \\
\pm \frac{1}{6} \\
\pm \frac{1}{8}\end{array}$ & $\begin{array}{l}4 \\
4 \\
4 \\
4 \\
4\end{array}$ \\
\hline $3(a)+3(c):$ & $\begin{array}{l}0 \\
\frac{1}{2} \\
0 \\
\frac{1}{2} \\
\frac{1}{2} \\
0 \\
\frac{1}{2}\end{array}$ & & $\begin{array}{l}0 \\
0 \\
\frac{1}{2} \\
\frac{1}{2} \\
0 \\
\frac{1}{2} \\
\frac{1}{2}\end{array}$ & $\begin{array}{l} \pm \frac{1}{3} \\
\pm \frac{1}{3} \\
\pm \frac{1}{3} \\
\pm \frac{1}{3} \\
0 \\
0 \\
0\end{array}$ & $\begin{array}{l}6 \\
6 \\
6 \\
6 \\
2 \\
2 \\
2\end{array}$ \\
\hline $3(a)+3(d)$ & $\begin{array}{l}0 \\
0 \\
0\end{array}$ & & $\begin{array}{l}0 \\
0 \\
0\end{array}$ & $\begin{array}{l} \pm \frac{1}{6} \\
\pm \frac{1}{3} \\
\frac{1}{2}\end{array}$ & $\begin{array}{r}12 \\
12 \\
6\end{array}$ \\
\hline
\end{tabular}

Thus, if the mercury atoms occupy the combination of threefold point positions $3(a)$ and $3(c)$, the only possible point positions left for the three iodine atoms are $3(b)$ and $3(d)$ since a statistical distribution over a sixfold point Acta Chem. Scand. 14 (1960) No. 10 
Table 3. Required and observed vectors Hg-Hg and Hg-I in the Patterson projection $P(u p w)$. The structure possibility: $6 \mathrm{Hg}$ in $3(a)+3(c)$. The calculated relative weights of the maxima due to the $\mathrm{Hg}-\mathrm{Hg}$ and $\mathrm{Hg}-\mathrm{I}$ vectors were calculated using the expression $v \sum_{i} f_{i} f_{j}$ where $v$ denotes the frequence of the vector and $f_{i}, f_{j}$ the scattering factors $\sum_{h, l} f_{i}$ of the atoms.

\begin{tabular}{|c|c|c|c|c|c|c|c|}
\hline$u \quad u$ & $w$ & $\begin{array}{c}\text { Vectors } \\
\mathrm{Hg}-\mathrm{Hg} \\
6 \mathrm{Hg} \text { in } \\
3(a)+3(c)\end{array}$ & $\begin{array}{c}\text { Vectors } \\
\text { Hg-I } \\
3 \text { I in } 3(b)\end{array}$ & $\begin{array}{c}\text { Vectors } \\
\text { Hg-I } \\
3 \mathrm{I} \text { in } 3(d)\end{array}$ & calc. I & calc. II & obs. \\
\hline $\begin{array}{l}0 \\
0\end{array}$ & $\begin{array}{l}\frac{1}{8} \\
\frac{1}{3}\end{array}$ & 6 & 4 & 2 & $\begin{array}{r}75 \\
178\end{array}$ & $\begin{array}{r}37 \\
178\end{array}$ & $\begin{array}{l}\overline{200} \\
400\end{array}$ \\
\hline $\begin{array}{ll}0 & \frac{1}{2} \\
\frac{1}{2} & 0 \\
\frac{1}{2} & \frac{1}{6} \\
\frac{1}{2} & \frac{1}{2} \\
\frac{1}{2} & \frac{1}{8} \\
\frac{1}{2} & \frac{1}{8}\end{array}$ & $\begin{array}{l}\frac{1}{2} \\
0 \\
\frac{1}{8} \\
\frac{1}{8} \\
\frac{1}{6}\end{array}$ & 6 & $\begin{array}{l}4 \\
2 \\
2\end{array}$ & $\begin{array}{l}4 \\
4 \\
2\end{array}$ & $\begin{array}{r}75 \\
\mathbf{5 9} \\
\mathbf{3 7} \\
\mathbf{1 7 8} \\
\mathbf{3 7}\end{array}$ & $\begin{array}{r}75 \\
59 \\
75 \\
178 \\
37\end{array}$ & $\begin{array}{r}200 \\
310 \\
20 \\
310 \\
0\end{array}$ \\
\hline
\end{tabular}

position is very improbable. Now, in Table 3, there are listed the required vectors mercury-mercury and mercury-iodine $(u, w)$ for the combinations:

$$
\begin{array}{ll}
6 \mathrm{Hg} \text { in } 3(a)+3(c), 3 \mathrm{I} \text { in } 3(b) \quad \text { (I) } \\
6 \mathrm{Hg} \text { in } 3(a)+3(c), 3 \mathrm{I} \text { in } 3(d) \quad \text { (II) }
\end{array}
$$

From the calculated and observed heights of the maxima in this table, it is clearly seen that the possibilities I and II are inconsistent with the experimental data.

The arrangements I and II seem to be impossible also from space considerations. Case $\mathrm{I}$ gives a very short distance Hg-I of only $1.7 \AA$ and case II offers $3(b)$ as the only possible position for the three sodium atoms which results in the very short distance $\mathrm{Hg}-\mathrm{Na}$ of $1.7 \AA$.

However, if the mercury atoms occupy the point position $6(f)$, then a point position for the iodine atoms can be found. This is explained in the following section.

The contribution of the iodine atoms to the X-ray intensities is relatively large and thus the observed Laue symmetry $6 / \mathrm{mmm}$ must be valid also for the iodine atoms. Attempts have been made to find a mercury arrangement equivalent to $3(a)+3(c)$ in $P 6_{2} 22$ and to derive possible iodine arrangements, satisfying the observed heights of the maxima of the Patterson projection $P(u p w)$, in the possible space groups $P 6 / \mathrm{mmm}$ (No. 191), $P \overline{6} 2 m$ (No. 189), $P \overline{6} \mathrm{m2}$ (No. 187), $P 6 \mathrm{~mm}$ (No. 183) and $P 622$ (No. 177). The results of these calculations were in no case satisfactory.

Thus, X-ray data were alone sufficient to make a decision between the two homometric mercury atom positions. The only possibility was, namely, the point position $6(f)$ in $P 6_{2} 22$ (No. 180). 
Table 4. Required vectors Hg-I in the Patterson functions. $6 \mathrm{Hg}$ in $6(f)+3 \mathrm{I}$ in $3(a), 3(b), 3(c)$ or $3(d)$.

\begin{tabular}{|c|c|c|c|c|}
\hline & $u$ & $v$ & $w$ & Relative weight \\
\hline $6(f), 3(a):$ & $\begin{array}{l}0 \\
0 \\
\frac{1}{2} \\
\frac{1}{2} \\
\frac{1}{2} \\
\frac{1}{2}\end{array}$ & $\begin{array}{l}\frac{1}{2} \\
\frac{1}{2} \\
0 \\
0 \\
\frac{1}{2} \\
\frac{1}{2}\end{array}$ & $\begin{array}{r}0 \\
\pm \frac{1}{3} \\
0 \\
\pm \frac{1}{3} \\
0 \\
\pm \frac{1}{3}\end{array}$ & $\begin{array}{l}2 \\
4 \\
2 \\
4 \\
2 \\
4\end{array}$ \\
\hline $6(f), 3(b):$ & $\begin{array}{l}0 \\
0 \\
\frac{1}{2} \\
\frac{1}{2} \\
\frac{1}{2} \\
\frac{1}{2}\end{array}$ & $\begin{array}{l}\frac{1}{2} \\
\frac{1}{2} \\
0 \\
0 \\
\frac{1}{2} \\
\frac{1}{2}\end{array}$ & $\begin{array}{r} \pm \frac{1}{6} \\
\\
\pm \frac{1}{2} \\
\pm \frac{1}{8} \\
\quad \frac{1}{2} \\
\pm \frac{1}{8} \\
\frac{1}{2}\end{array}$ & $\begin{array}{l}4 \\
2 \\
4 \\
2 \\
4 \\
2\end{array}$ \\
\hline $6(f), 3(c):$ & $\begin{array}{l}0 \\
0 \\
0 \\
\frac{1}{2} \\
\frac{1}{2} \\
\frac{1}{2} \\
\frac{1}{2}\end{array}$ & $\begin{array}{l}0 \\
\frac{1}{2} \\
\frac{1}{2} \\
0 \\
0 \\
\frac{1}{2} \\
\frac{1}{2}\end{array}$ & $\begin{array}{r} \pm \frac{1}{3} \\
0 \\
\pm \frac{1}{8} \\
0 \\
\pm \frac{1}{3} \\
0 \\
\pm \frac{1}{3}\end{array}$ & $\begin{array}{l}6 \\
2 \\
2 \\
2 \\
2 \\
2 \\
2\end{array}$ \\
\hline $6(f), 3(d):$ & $\begin{array}{l}0 \\
0 \\
0 \\
\frac{1}{2} \\
\frac{1}{2} \\
\frac{1}{2} \\
\frac{1}{2}\end{array}$ & $\begin{array}{l}0 \\
\frac{1}{2} \\
\frac{1}{2} \\
0 \\
0 \\
\frac{1}{2} \\
\frac{1}{2}\end{array}$ & $\begin{array}{r} \pm \frac{1}{6} \\
\pm \frac{1}{6} \\
\frac{1}{2} \\
\pm \frac{1}{6} \\
\frac{1}{2} \\
\pm \frac{1}{6} \\
\frac{1}{2}\end{array}$ & $\begin{array}{l}6 \\
2 \\
2 \\
2 \\
2 \\
2 \\
2\end{array}$ \\
\hline
\end{tabular}

THE POSITIONS OF THE IODINE ATOMS

Since the six mercury atoms occupy the point position $6(f)$ with $z=0.333$, it is thus possible for the three iodine atoms to occupy one of the threefold point positions $3(a), 3(b), 3(c)$ or $3(d)$. The required mercury-iodine vectors $u, v, w$ for the four different cases are listed in Table 4. From the Patterson projection $P(u p w)$ (Fig. 1), it is seen that it is impossible for the relatively heavy iodine atoms to occupy one of the threefold point positions $3(b)$ or $3(d)$ because the projection does not show any maxima at $u=0, w= \pm \frac{1}{6}$ or $u=$ $0, w=\frac{1}{2}$. On the other hand it is seen that the expected vectors $\mathrm{Hg}$-I for the remaining possibilities for the iodine atoms $3(a)$ and $3(c)$ correspond to the calculated projection. However, the maximum of the projection $P(u p w)$ at $u=0, w=\frac{1}{3}$ is about $30 \%$ higher than that at $u=\frac{1}{2}, w=\frac{1}{3}$. This can only be explained if the iodine atoms are situated in the point position 3(c) (Table 5).

To confirm that $3(c)$ is the actual point position for the iodine atoms, threedimensional electron density calculations were performed using 860 reflexions (not independent) obtained with $\mathrm{Cu} K$ radiation. Theoretically, the Fourier projection $\varrho(x y p)$ should differentiate between the possibilities $3(a)$ and 
Table 5. Required and observed vectors $\mathrm{Hg} \cdot \mathrm{Hg}$ and $\mathrm{Hg} \cdot \mathrm{I}$ in the Patterson projection $P(u p w)$. The structure possibility: $6 \mathrm{Hg}$ in $6(f) . \mid$ The calculations were performed as in Table 3 .

\begin{tabular}{|cc|c|c|c|c|c|c|}
\hline$u$ & $w$ & $\begin{array}{c}\text { Vectors } \\
\text { Hg-Hg } \\
\text { 6 Hg in 6(f) }\end{array}$ & $\begin{array}{c}\text { Vectors } \\
\text { Hg-I } \\
\text { 3 I in 3 }(a)\end{array}$ & $\begin{array}{c}\text { Vectors } \\
\text { Hg-I } \\
\text { 3 I in 3 }(c)\end{array}$ & $\begin{array}{c}\text { Rel. weight } \\
\text { calc. } \\
3(a), 6(f)\end{array}$ & $\begin{array}{c}\text { Rel. weight } \\
\text { calc. } \\
3(c), 6(f) .\end{array}$ & $\begin{array}{c}\text { Rel. weight } \\
\text { obs. }\end{array}$ \\
\hline & & & & & & \\
0 & & & 2 & 4 & 332 & 395 & 400 \\
$\frac{1}{2}$ & 0 & 4 & 4 & 4 & 298 & 298 & 310 \\
$\frac{1}{2}$ & $\frac{1}{3}$ & 6 & 4 & 2 & 395 & 332 & 310 \\
\hline
\end{tabular}

$3(c)$ but, as it is based on only a few reflexions, its exactness is much less than that of the sections of the three-dimensional electron density space. Hence, the electron density sections $\varrho(x y z)$ at $z=0, \frac{1}{6}, \frac{1}{3}, \frac{1}{2}$ and $\frac{2}{3}$ were computed. The calculations were at first based on $F$ values derived in the usual way from the visually estimated intensities of the reflexions and on the signs and values of the phase angles $\alpha_{h k l}=\operatorname{arctg}\left(\frac{B}{A}\right)_{h k l}$ determined from the mercury contributions for all reflexions except 54 of the weakest.

The sections show high maxima at $0 \frac{1}{2} 0, \frac{1}{2} \frac{1}{2} 0, \frac{1}{2} 0 \frac{1}{3}, 0 \frac{1}{2} \frac{1}{3}, \frac{1}{2} 0 \frac{2}{3}$ and $\frac{1}{2} \frac{1}{2} \frac{2}{3}$ which is espected for mercury atoms occupying the point position $6(f)$ that was assumed when calculating the values of the phase angles. Moreover, maxima with a height correct for an iodine atom appear at $\frac{1}{2} 00, \frac{1}{2} \frac{1}{2} \frac{1}{3}$ and and $0 \frac{1}{2} \frac{2}{3}$, indicating that the iodine atoms are situated in the point position $3(c)$. Apart from these maxima, there are only small maxima in the sections $\varrho(x y 0), \varrho\left(x y \frac{1}{3}\right)$ and $\varrho\left(x y \frac{2}{3}\right)$ and they can be ascribed to diffraction effects from the mercury and iodine atoms and to sodium and oxygen atoms. The sections $\varrho\left(x y \frac{1}{6}\right)$ and $\varrho\left(x y \frac{1}{2}\right)$ show small peaks at $x=0, y=0$ (Fig. 2). Otherwise, these sections do not show any peaks with a height differing from the general background by more than that expected for diffraction effects from the heavy atoms. Using calculated $F$ values (the contributions of the mercury atoms only being taken into account) and the same phase angles as above, the electron density sections $\varrho(x y 0)$ and $\varrho\left(x y \frac{1}{3}\right)$ were also computed. These sections did not. show any maxima at $\frac{1}{2} 00$ and $\frac{1}{2} \frac{1}{2} \frac{1}{3}$ - only the high maxima at $0 \frac{1}{2} 0, \frac{1}{2} \frac{1}{2} 0, \frac{1}{2} 0 \frac{1}{3}$ and $0 \frac{1}{2} \frac{1}{3}$. This further confirms that the point position of the iodine atoms is $3(c)$.

The electron density sections $\varrho(x y 0), \varrho\left(x y \frac{1}{3}\right)$ (Fig. 2) and $\varrho\left(x y_{3}^{2}\right)$ were then recalculated using the observed $F$ values and the signs and values of the phase angles determined from the contributions of the mercury and iodine atoms for all observed reflexions. There was no difference worth mentioning between these sections and those obtained by the previous calculations. To obtain further proof concerning the positions of the iodine atoms and if possible to get some information on the positions of the sodium and the oxygen atoms, first the mercury atoms and then both the mercury and iodine atoms (Fig. 2) were substracted from $\varrho(x y 0)$ and $\varrho\left(x y \frac{1}{3}\right)$. In this way, most of the diffraction 

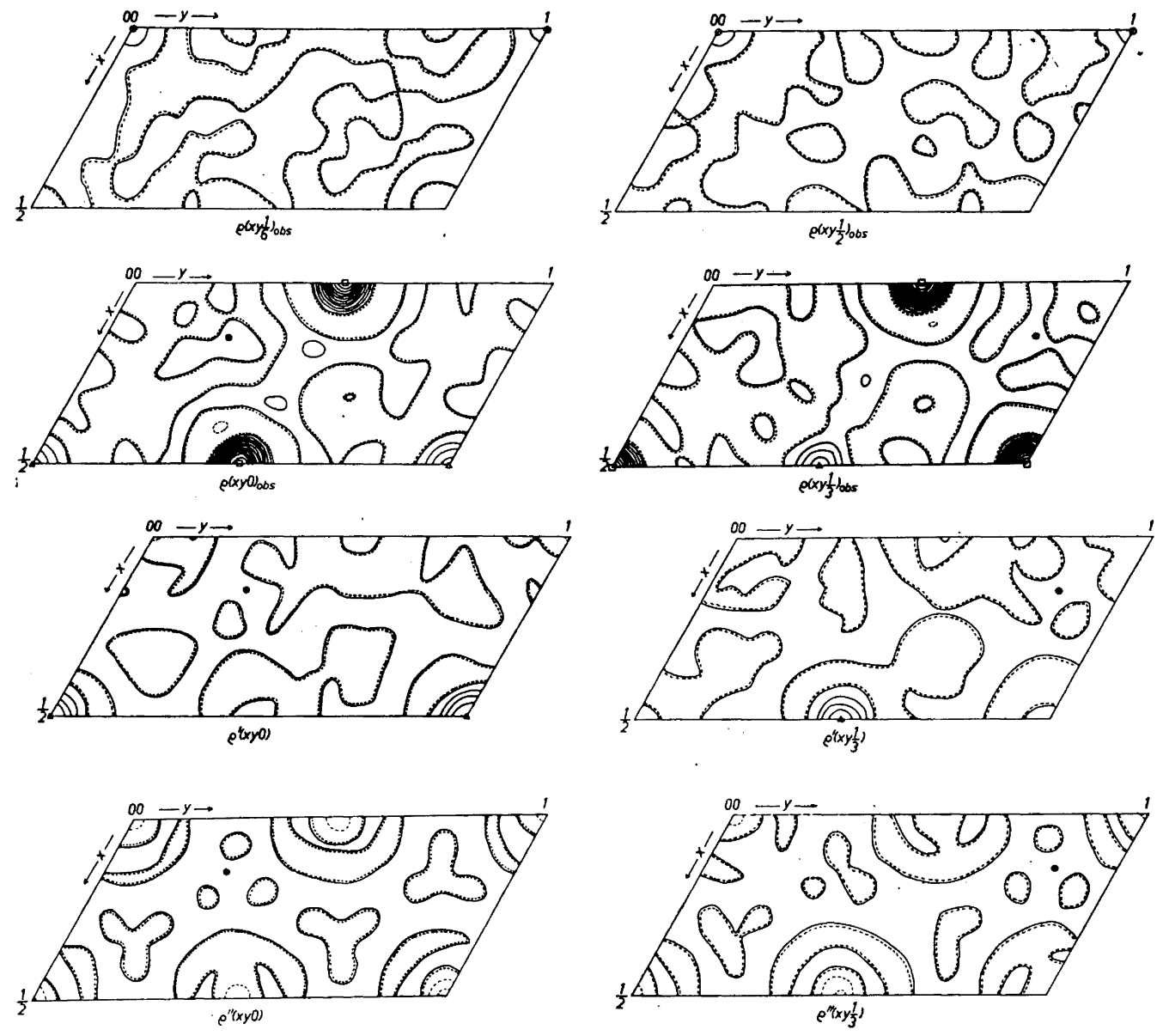

Fig. 2. The observed electron density sections $\varrho\left(x y \frac{1}{6}\right), \varrho\left(x y \frac{1}{2}\right), \varrho(x y 0)$ and $\varrho\left(x y \frac{1}{3}\right)$, the electron density sections $\varrho^{\prime}(x y 0)$ and $\varrho^{\prime}\left(x y \frac{1}{3}\right)$, where the contributions of the mercury atoms are substracted from $\varrho(x y 0)$ and $\varrho\left(x y \frac{1}{3}\right)$, and the electron density sections $\varrho^{\prime \prime}(x y 0)$ and $\varrho^{\prime \prime}\left(x y \frac{1}{3}\right)$, where the contributions of the mercury and of the iodine atoms have been substracted from $\varrho(x y 0)$ and $\varrho\left(x y_{\frac{1}{3}}\right)$. The final mercury $(\square)$, iodine $(\Delta)$, oxygen $(\bullet)$ and sodium $(\mathrm{O})$ atom positions are indicated. Dashed lines indicate negative values.

effects $s^{y}$ from the heavy atoms should disappear and only maxima indicating the iodine atoms and possibly small maxima indicating the sodium and oxygen atoms (Fig. 2) should be obtained. As expected, these calculations show clearly that the point position of the three iodine atoms is $3(c)$.

The temperature factor that should have been introduced in these calculations was found to be negligible when calculated by the ordinary procedure. Probably, it approximately cancels out with the absorption effects. 
The positions for the sodium and oxygen atoms which could possibly be obtained from these sections would doubtless be rather uncertain. One reason is that the Fourier series has in fact been broken at $l=5$, another one is the dominant scattering power for $\mathrm{X}$-rays of the heavy atoms. No attempt was therefore made to utilize the information obtainable from these small maxima for the determination of the positions of the light atoms.

\section{THE POSITIONS OF THE LIGHT ATOMS}

The above discussion has shown that the six mercury atoms occupy the point position $6(f)$ and the three iodine atoms the point position $3(c)$ in the space group $P 6_{2} 22$ (No. 180). Consequently the holes between these atoms must also possess the symmetry $P_{6} 22$. It is therefore probable that the sodium and the oxygen atoms have the same symmetry - it will be seen later on that this is supported by the results of a neutron diffraction investigation. Now, in $P_{6} \mathbf{2}_{2}$, the only positions left for the three sodium atoms are $3(a), 3(b)$ and $3(d)$ (see p. 2200). The position $3(d)$ would result in a very short distance $\mathrm{Hg}-\mathrm{Na}$ of only $1.7 \AA$ and can therefore be excluded. The remaining positions $3(a)$ and $3(b)$ are, with regard to the distances $\mathrm{Hg}-\mathrm{Na}$ and $\mathrm{I}-\mathrm{Na}$, equally probable for the sodium atoms. In the unit cell, there are in addition six oxygen atoms. The positions left for them are therefore: $6(i), 6(j), 6(h), 6(g), 6(f)$, $6(e)$, the combinations of the threefold point positions $3(a)+3(d)$ and $3(b)$ $+3(d)$ and the less probable arrangement of a statistical distribution over $12(k)$. The possibilities $3(a)+3(d), 3(b)+3(d), 6(e)$ and $6(f)$ would give a very short distance of $1.7 \AA$ between $\mathrm{Hg}-\mathrm{O}, \mathrm{O}-\mathrm{O}$ or I-O and can thus be ruled out. Hence, the possibilities for the oxygen atoms are limited to $6(j), 6(i), 6(h)$ and $6(g)$. To find the arrangement of the light atoms according to the possible point positions, it is necessary to consider the geometry of the holes in the structure. The following distances from the mercury, sodium and iodine atoms to the oxygen atoms were assumed when drawing $x y$-sections of the unit cell at different $z$ values:

$$
\mathrm{Hg}-\mathrm{O} \geqslant 2.0 \AA, \quad \mathrm{Na}-\mathrm{O} \geq 2.3 \AA, \quad \mathrm{I}-\mathrm{O} \geq 3.0 \AA .
$$
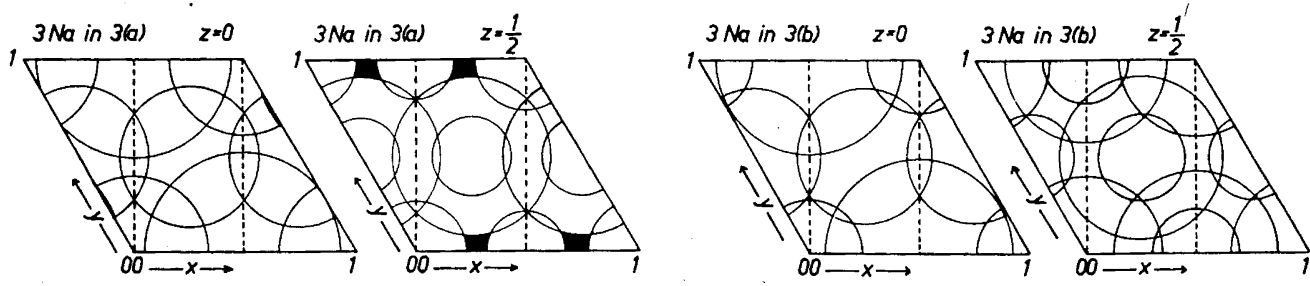

Fig. 3. Survey over the space which is free (black areas) for the oxygen atoms in the planes $z=0$ and $z=0.50$. The point position of the sodium atoms is assumed to be $3(a)$ and $3(b)$. The function $y=2 x$ is drawn with dashed lines. 
The results are given in Fig. 3. From these figures, it can be concluded that the possible positions for the sodium and oxygen atoms are:

A: $3 \mathrm{Na}$ in $3(a), 6 \mathrm{O}$ in $6(j)$ with $x \sim 0.40$.

$\mathrm{B}: 3 \mathrm{Na}$ in $3(a), 6 \mathrm{O}$ in $6(h)$ with $0.30 \geqslant x \geqslant 0.20$.

C: $3 \mathrm{Na}$ in $3(b), 6 \mathrm{O}$ in $6(i)$ with $x \sim 0.15$.

The combinations $\mathrm{A}$ and $\mathrm{B}$ give rise to an arrangement for the mercury and the oxygen atoms which seems very unusual. Each mercury atom is coordinated to two oxygen atoms and each oxygen atom to two mercury atoms, giving an arrangement of isolated rhombs of the composition $\mathrm{Hg}_{2} \mathrm{O}_{2}$. The distances from the mercury and sodium atoms to the oxygen atoms are:

$\mathrm{A}: x_{0}=0.40, \mathrm{Hg}-\mathrm{O}=2.6 \AA, \mathrm{Na}-\mathrm{O}=2.1 \AA$.

$\mathrm{B}: x_{0}=0.25, \mathrm{Hg}-\mathrm{O}=2.4 \AA, \mathrm{Na}-\mathrm{O}=2.4 \AA$.

With the combination $\mathrm{C}$, the arrangement of the mercury and oxygen atoms is made up of planar zig-zag chains - $\mathrm{Hg}-\mathrm{O}-\mathrm{Hg}$ - with all distances $\mathrm{Hg}-\mathrm{O}$ equal to $2.0 \AA$, the oxygen parameter being 0.15 . The structure of orthorhombic mercury(II)oxide described earlier ${ }^{1}$ is built up of such chains with the same distance $\mathrm{Hg}-\mathrm{O}$ and the same values for the angles $\mathrm{O}-\mathrm{Hg}-\mathrm{O}$ and $\mathrm{Hg}-\mathrm{O}-\mathrm{Hg}$ as given here for the possibility $\mathrm{C}$. It seems therefore very probable that the combination $\mathrm{C}$ is the most applicable one for this structure problem.

In order to make possible an objective decision between the three geometrically possible structures, the investigation was supplemented by a neutron diffraction study.

\section{NEUTRON DIFFRACTION STUDIES}

The coherent scattering amplitudes of mercury, iodine, sodium and oxygen for neutrons and $\mathrm{X}$-rays are given in the following table:

\begin{tabular}{lcc}
\multicolumn{2}{l}{ Scattering amplitude } & $\left(10^{-12} \mathrm{~cm}\right)$, Ref. ${ }^{11}$ \\
& Neutron & X-ray $\left(\Theta=0^{\circ}\right)$ \\
$\mathrm{Hg}$ & 1.31 & 22.5 \\
$\mathrm{I}$ & 0.52 & 15.0 \\
$\mathrm{Na}$ & 0.35 & 3.09 \\
O & 0.58 & 2.25
\end{tabular}

The amplitude values for neutrons are independent of the scattering angle while those for X-rays decrease with $\Theta$ and relatively more so for sodium and oxygen than for mercury and iodine. Therefore, it seems rather unlikely that one can locate these light atoms from the observed $\mathrm{X}$-ray data but it is evident that neutron diffraction work would provide much better possibilities for the determination of the sites. Since it was impossible to get a crystal large enough for single crystal investigations with the apparatus available, the neutron diffraction work was carried out on a powder sample in a flat aluminium container. Since the cross section for true absorption is very large

Acta Chem. Scand. 14 (1960) No. 10 

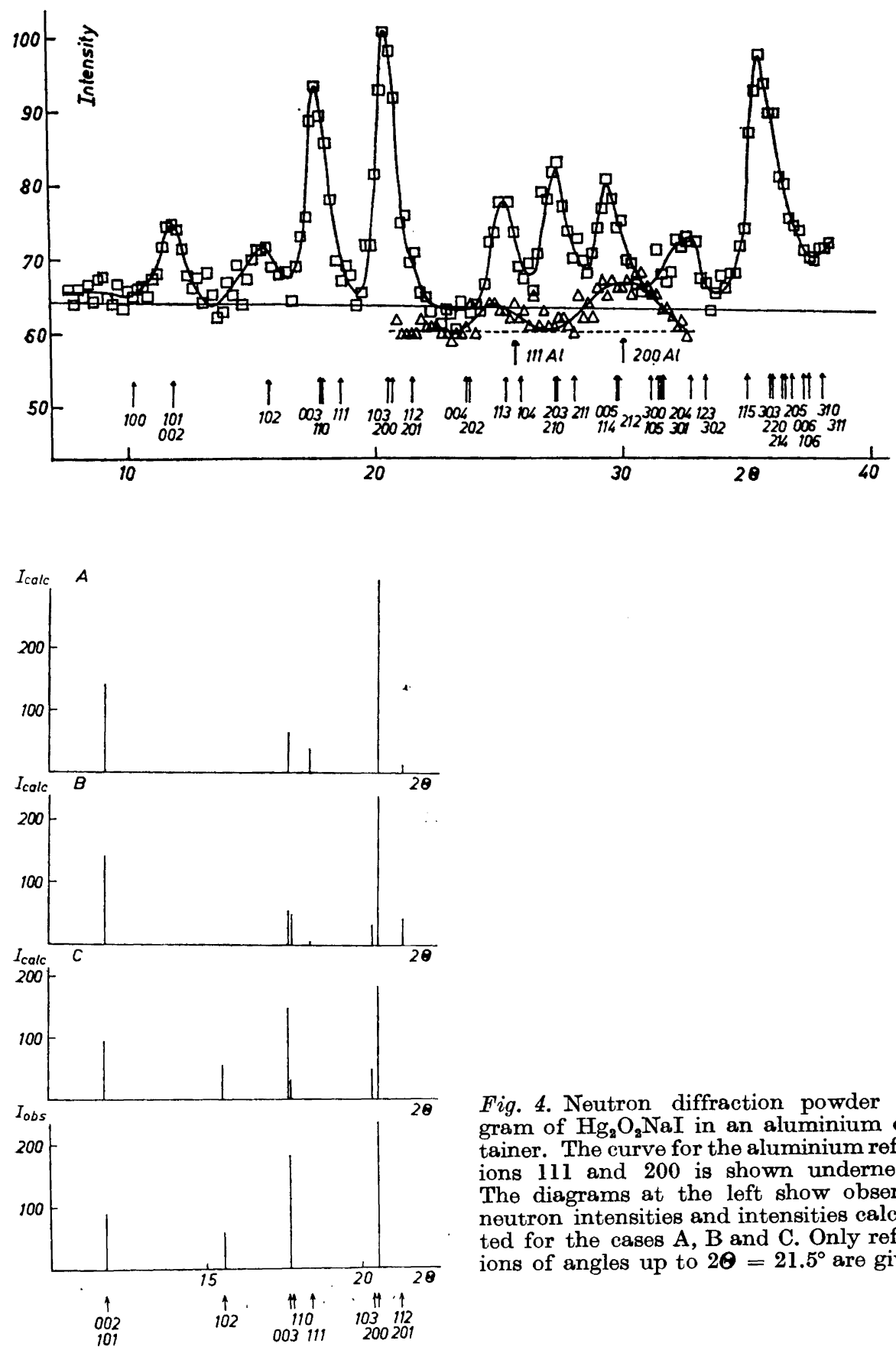

Fig. 4. Neutron diffraction powder diagram of $\mathrm{Hg}_{2} \mathrm{O}_{2} \mathrm{NaI}$ in an aluminium container. The curve for the aluminium reflexions 111 and 200 is shown underneath. The diagrams at the left show observed neutron intensities and intensities calculated for the cases A, B and C. Only reflexions of angles up to $2 \Theta=21.5^{\circ}$ are given. 
Table 6. Observed neutron intensities from a powdered sample of $\mathrm{Hg}_{2} \mathrm{O}_{2} \mathrm{NaI}$. The intensities of the coinciding reflexions 113 and 104, from 005 to 212 and from 300 to 302 were corrected for the contributions of the aluminium reflexions 111 and 200. The intensities were calculated for the case $\mathrm{C}(3(b), 6(i))$ : I. neglecting the influence of the oxygen atoms and II. taking the influence of the oxygen atoms into account. Icalcr and $I$ calc II are normalized so as to give the best agreement with Iobs.

\begin{tabular}{|c|c|c|c|c|c|c|c|}
\hline$h k l$ & $I_{\mathrm{obs}}$ & $I_{\text {calc }_{\text {I }}}$ & $I_{\mathrm{calc}_{\mathrm{II}}}$ & $h k l$ & $I_{\mathrm{obs}}$ & $I_{\mathrm{calc}_{\mathrm{I}}}$ & $I_{\text {calc }_{\text {II }}}$ \\
\hline $\begin{array}{l}101 \\
002\end{array}$ & 89 & 40 & 93 & $\begin{array}{l}005 \\
114 \\
212\end{array}$ & 66 & 20 & 39 \\
\hline 102 & 59 & 23 & 54 & & & & \\
\hline $\begin{array}{l}003 \\
110\end{array}$ & 182 & 116 & 176 & $\begin{array}{l}300 \\
204 \\
105\end{array}$ & & & \\
\hline $\begin{array}{l}103 \\
200\end{array}$ & 235 & 404 & 227 & $\begin{array}{l}301 \\
123 \\
302\end{array}$ & 128 & 102 & 103 \\
\hline $\begin{array}{l}112 \\
201\end{array}$ & & & & $\begin{array}{l}115 \\
303\end{array}$ & & & \\
\hline $\begin{array}{l}004 \\
202\end{array}$ & - & 0 & 1 & $\begin{array}{l}220 \\
221 \\
214\end{array}$ & & & \\
\hline $\begin{array}{l}113 \\
104\end{array}$ & 84 & 73 & 106 & $\begin{array}{l}205 \\
006 \\
106\end{array}$ & 290 & 206 & 300 \\
\hline $\begin{array}{l}203 \\
210 \\
211\end{array}$ & 143 & 293 & 178 & $\begin{array}{l}310 \\
222 \\
311\end{array}$ & & & \\
\hline
\end{tabular}

for mercury, the powder sample had to be thin and the observed neutron intensities were therefore low. The aluminium holder was chosen so that $\mu \cdot t=0.439$ where $\mu$ is the linear absorption coefficient of the compound

Table \%. Observed neutron intensities from a powdered sample of $\mathrm{Hg}_{2} \mathrm{O}_{2} \mathrm{NaI}$ and intensities calculated for the structure possibility C. The parameter for the oxygen atom position was varied within the limits $0.10 \leq x_{\mathrm{O}} \leq 0.20$.

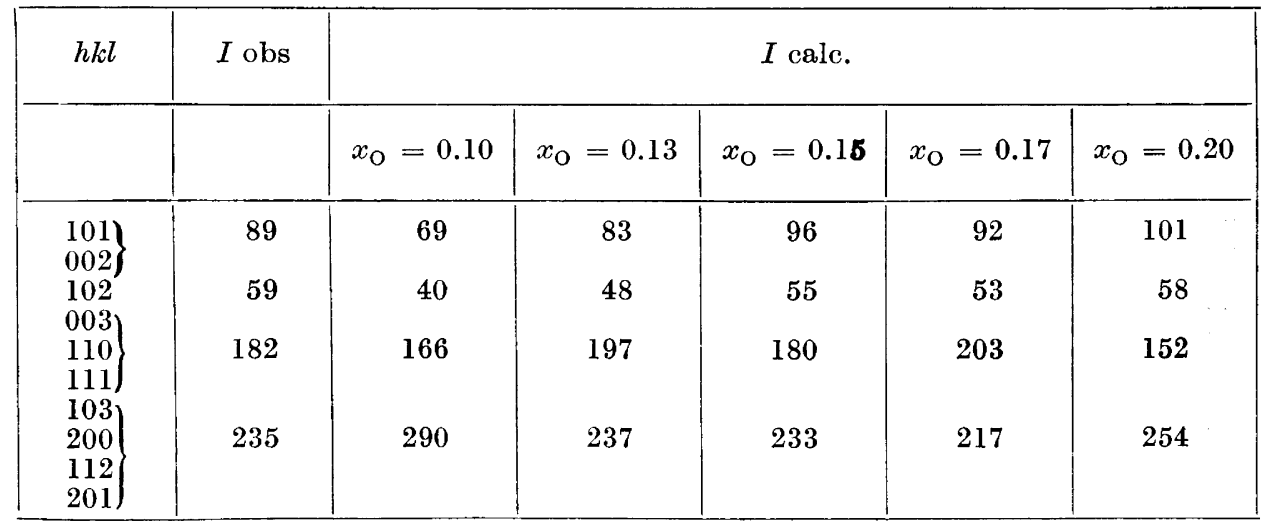


Table 8. Calculated and observed structure factors $h k l$ for $\mathrm{Hg}_{2} \mathrm{O}_{2} \mathrm{NaI}$.

\begin{tabular}{|c|c|c|c|c|c|}
\hline$h k l$ & $\left|F_{\text {calc }}\right|$ & $\left|F_{\text {obs }}\right|$ & $h k l$ & $\left|F_{\text {calc }}\right|$ & $\left|F_{\text {obs }}\right|$ \\
\hline 010 & 160 & 149 & 162 & 34 & 36 \\
\hline 020 & 556 & 502 & 222 & 2 & - \\
\hline 030 & 147 & 192 & 232 & 42 & 38 \\
\hline 040 & 430 & 418 & 242 & 5 & - \\
\hline 050 & 117 & 122 & 252 & 29 & 33 \\
\hline 060 & 369 & 355 & 262 & 6 & - \\
\hline 070 & 84 & 124 & 332 & 28 & 33 \\
\hline 110 & 173 & 236 & 342 & 39 & 38 \\
\hline 120 & 146 & 195 & 352 & 34 & 36 \\
\hline 130 & 122 & 162 & 442 & 3 & - \\
\hline 140 & 119 & 154 & $\begin{array}{llll}0 & 0 & 3\end{array}$ & 579 & 619 \\
\hline 150 & 108 & 99 & 013 & 198 & 195 \\
\hline 160 & 93 & 83 & 023 & 463 & 325 \\
\hline 220 & 490 & 418 & 033 & 179 & 215 \\
\hline 230 & 106 & 112 & 043 & 379 & 401 \\
\hline 240 & 380 & 388 & 053 & 144 & 163 \\
\hline 250 & 106 & 83 & 063 & 336 & 329 \\
\hline 260 & 315 & 281 & 073 & 103 & 117 \\
\hline 330 & 110 & 145 & 113 & 206 & 178 \\
\hline 340 & 107 & 107 & 123 & 179 & 183 \\
\hline 350 & 95 & 83 & 133 & 155 & 195 \\
\hline 440 & 335 & 289 & 143 & 148 & 185 \\
\hline 011 & 66 & 64 & 153 & 133 & 149 \\
\hline 021 & 5 & 一 & 163 & 113 & 124 \\
\hline 031 & 29 & 30 & 223 & 427 & 274 \\
\hline 041 & 8 & - & 233 & 136 & 135 \\
\hline $\begin{array}{llll}0 & 5 & 1\end{array}$ & 43 & 46 & 243 & 342 & 383 \\
\hline 061 & 2 & - & 253 & 128 & 144 \\
\hline 071 & 32 & 33 & 263 & 290 & 282 \\
\hline 111 & 26 & 13 & 333 & 137 & 167 \\
\hline 121 & 58 & 58 & 343 & 129 & 134 \\
\hline 131 & 49 & 46 & 353 & 113 & 109 \\
\hline 141 & 29 & 33 & 443 & 308 & 291 \\
\hline 151 & 41 & 51 & 014 & 58 & 54 \\
\hline 161 & 34 & 45 & 024 & 2 & - \\
\hline 221 & 1 & - & 034 & 29 & 31 \\
\hline 231 & 42 & 40 & 044 & 6 & - \\
\hline 241 & 6 & - & 054 & 41 & 48 \\
\hline 251 & 29 & 26 & 064 & 0 & - \\
\hline 261 & 7 & - & 074 & 32 & 28 \\
\hline 331 & 28 & 38 & 114 & 27 & 25 \\
\hline 341 & 39 & 45 & 124 & 52 & 45 \\
\hline 3 & 34 & 41 & 134 & 45 & 46 \\
\hline 4 & 3 & - & 144 & 28 & 30 \\
\hline 0 & 64 & 51 & 154 & 39 & 46 \\
\hline 0 & 5 & - & 164 & 33 & 33 \\
\hline 0 & 29 & 26 & 224 & 2 & - \\
\hline 0 & 7 & - & 234 & 40 & 46 \\
\hline 0 & 42 & 41 & 244 & 4 & - \\
\hline 0 & 2 & - & 4 & 29 & 25 \\
\hline 072 & 32 & 46 & 4 & 27 & 36 \\
\hline 112 & 26 & 31 & 344 & 38 & 46 \\
\hline 122 & 57 & 61 & 354 & 33 & 33 \\
\hline 132 & 48 & 56 & 444 & 2 & - \\
\hline 1 & 29 & 33 & & & \\
\hline & 41 & 50 & & & \\
\hline
\end{tabular}

Acta Chem. Scand. 14, (1960) No. 10 

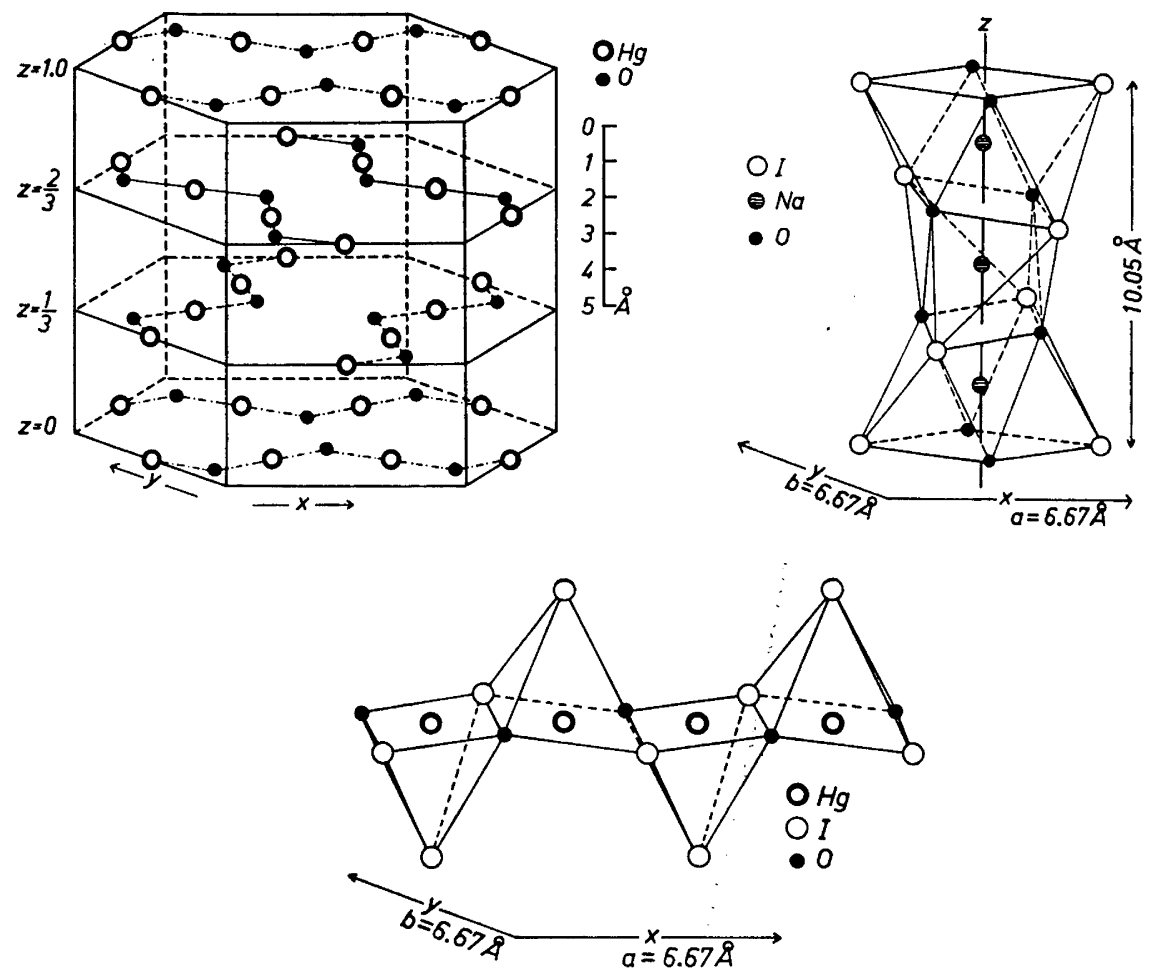

Fig. 5. Schematic drawings showing the infinite planar chains $-\mathrm{O}-\mathrm{Hg}-\mathrm{O}-\mathrm{Hg}-$, lying perpendicularly to the $c$ axis at the heights $z=0, \frac{1}{3}$ and $\frac{2}{3}$, showing a chain of deformed Archimedean square antiprisms, running parallel to the $c$ axis and showing a chain of pyramids, lying perpendicularly to the $c$ axis. Each Archimedean antiprism is made up of four iodine and four oxygen atoms with one sodium atom in its centre. Each pyramid is made up of three iodine and two oxygen atoms with one mercury atom in the centre of its base plane.

and $t$ the length of the sample. The reactor was run at a level of $450 \mathrm{~kW}$. The diffracted intensity was measured at intervals of $0.2^{\circ}$ scattering angle, counts being taken during the time necessary for accumulating 500000 neutron counts in the monitor for the incident neutron beam. The curve that was obtained by plotting the counts against the angles is given in Fig. 4. The observed intensities, obtained by measuring the areas under the peaks with a planimeter and correcting for the contribution of the aluminium reflexions 111 and 200 from the container, are given in Table 6. Due to serious overlapping, only the intensities of the reflexions at low $\Theta$ angles could be evaluated with accuracy. The neutron intensities of the observed reflexions were calculated for the structure possibilities A, B and C assuming the parameter values given above and were compared with the observed intensities in a neutron diffraction diagram. The result is given in Fig. 4, from which it is

Acta Chem. Scand. 14. (1960) No. 10 


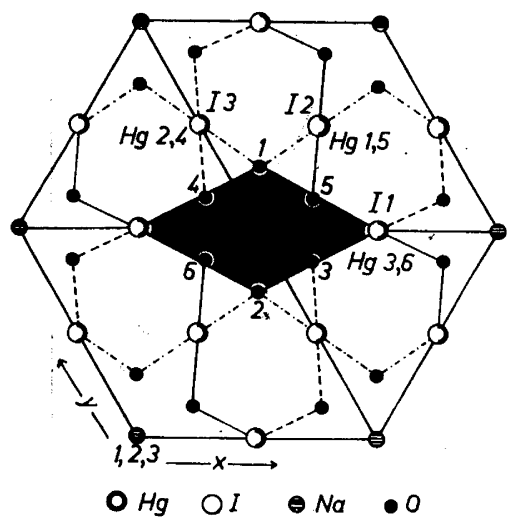

$\mathrm{Na} 1 z=1 / 6 ; \quad \mathrm{Hg} 1,2 \quad z=0$; $\mathrm{Na} 2 z=1 / 2 ; \quad \mathrm{Hg} 3,4 \quad z=1 / 3$; $\mathrm{Na} 3 z=5 / 6 ; \quad \mathrm{Hg} 5,6 \quad z=2 / 3$;
Fig. 6: The $x y$ projection of the structure of $\mathrm{Hg}_{2} \mathrm{O}_{2} \mathrm{NaI}$ showing the coordination of the atoms. The infinite planar chain $-\mathrm{O}-\mathrm{Hg}-\mathrm{O}-$ at $z=0$ is indicated by $\mathrm{a}$ dasheddotted line, that at $z=0.33$ by $\mathbf{a}$ dotted line and that at $z=0.67$ by a full line. The base plane of the deformed Archimedean antiprism at, $z=0$ is indicated by the black area.

$$
\begin{array}{llll}
\text { I 1 } & z=0 & \text { O 1,2 } & z=0 \\
\text { I 2 } & z=1 / 3 ; & \text { O 3,4 } & z=1 / 3 \\
\text { I 3 } & z=2 / 3 ; & \text { O 5,6 } & z=2 / 3
\end{array}
$$

clearly seen that the possibility $C$ is the only one that is consistent with the experimental data. For the case $\mathrm{C}$, a systematic variation of the parameter for the oxygen atom position gave the best agreement between observed and calculated intensities when $x_{\mathrm{o}}=0.15$ (Table 7). The neutron intensities of the reflexions were calculated according to Bacon ${ }^{12}$, the influence of the temperature factor being, however, neglected.

\section{CORRELATION OF X-RAY AND NEUTRON DIFFRACTION INTENSITIES}

The point positions and parameters of the atoms having been determined, the X-ray structure factors of the reflexions $h k l$ were"then calculated and compared with the observed ones (cf. Table 8). The influence of the temperature factor was, however, neglected. The agreement between observed and calculated values was found to be good. To obtain a criterion of the correspondence, the reliability factor $R=\frac{\Sigma|| F_{\text {obs }}|-| F_{\text {calc }}||}{\Sigma\left|F_{\text {obs }}\right|}$ was calculated according to Booth ${ }^{13}$ and found to be $13.7 \%$ (absent reflexions included) or $13.0 \%$ (absent reflexions not included), showing that the structure should be essentially correct as regards the heavy atoms.

To reduce the influence of orientation effects observed in the Guinier photogram (e.g. the reflexion 303), accurate values for the intensities of the $\mathrm{X}$-ray powder reflexions were measured for a sample mixed with gum arabic (1:3) using a Geiger-Mueller diffractometer. The observed intensities obtained by measuring the areas under the peaks are given in Table 1. For overlapping reflexions, the sum of the intensities are given. As seen, the agreement between observed and calculated intensities is good (Table 1).

The calculated and observed neutron intensities for all reflexions that could be evaluated are given in Table 6. The accuracy of the observed reflexions 


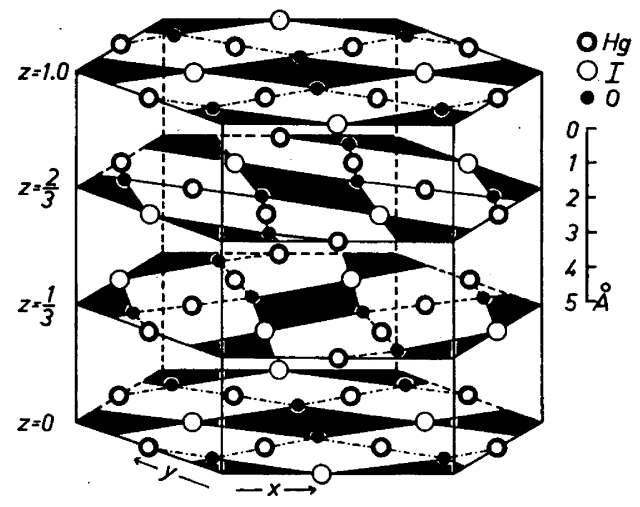

Fig. 7. A schematic drawing showing the connection between the infinite planar chains $-\mathrm{O}-\mathrm{Hg}-\mathrm{O}-$ and the base planes of the Archimedean antiprisms. The base planes are indicated by black areas.

Table 9. Interatomic distances in the structure of $\mathrm{Hg}_{2} \mathrm{O}_{2} \mathrm{NaI}$. The atoms are named as in the $x y$ projection (Fig. 6).

\begin{tabular}{|c|c|c|c|}
\hline $\begin{array}{l}\mathrm{Hg}_{1}-\mathrm{O}_{1}, \mathrm{O}_{8} \\
\mathrm{Hg}_{2}-\mathrm{O}_{1}, \mathrm{O}_{2} \\
\mathrm{Hg}_{3}-\mathrm{O}_{3}, \mathrm{O}_{4} \\
\mathrm{Hg}_{4}-\mathrm{O}_{3}, \mathrm{O}_{4} \\
\mathrm{Hg}_{5}-\mathrm{O}_{5}, \mathrm{O}_{6} \\
\mathrm{Hg}_{8}-\mathrm{O}_{8}, \mathrm{O}_{6}\end{array}$ & $\begin{array}{l}2.03 \AA \\
2.03 \AA \\
2.03 \AA \\
2.03 \AA \\
2.03 \AA \\
2.03 \AA\end{array}$ & $\begin{array}{l}\mathrm{Hg}_{1}-\mathrm{Hg}_{2} \\
\mathrm{Hg}_{1}-\mathrm{Hg}_{5} \\
\mathrm{Hg}_{2}-\mathrm{Hg}_{4} \\
\mathrm{Hg}_{3}-\mathrm{Hg}_{4} \\
\mathrm{Hg}_{3}-\mathrm{Hg}_{6} \\
\mathrm{Hg}_{5}-\mathrm{Hg}_{6}\end{array}$ & $\begin{array}{l}3.33 \AA \\
3.35 \AA \\
3.35 \AA \\
3.33 \AA \\
3.35 \AA \\
3.33 \AA\end{array}$ \\
\hline $\begin{array}{l}\mathrm{Na}_{1}-\mathrm{O}_{1}, \mathrm{O}_{2}, \mathrm{O}_{3}, \mathrm{O}_{4} \\
\mathrm{Na}_{2}-\mathrm{O}_{3}, \mathrm{O}_{4}, \mathrm{O}_{5}, \mathrm{O}_{6} \\
\mathrm{Na}_{3}-\mathrm{O}_{1}, \mathrm{O}_{2}, \mathrm{O}_{5}, \mathrm{O}_{6} \\
\mathrm{Na}_{1}-\mathrm{I}_{1}, \mathrm{I}_{2} \\
\mathrm{Na}_{2}-\mathrm{I}_{2}, \mathrm{I}_{3} \\
\mathrm{Na}_{3}-\mathrm{I}_{1}, \mathrm{I}_{3}\end{array}$ & $\begin{array}{l}2.41 \AA \\
2.41 \AA \\
2.41 \AA \\
3.73 \AA \\
3.73 \AA \\
3.73 \AA\end{array}$ & $\begin{array}{l}\mathrm{Na}_{1}-\mathrm{Na}_{2} \\
\mathrm{Na}_{1}-\mathrm{Na}_{3} \\
\mathrm{Na}_{2}-\mathrm{Na}_{3} \\
\mathrm{I}_{1}-\mathrm{I}_{2}, \mathrm{I}_{3} \\
\mathrm{I}_{2}-\mathrm{I}_{3}\end{array}$ & $\begin{array}{l}3.35 \AA \\
3.35 \AA \\
3.35 \AA \\
4.73 \AA \\
4.73 \AA\end{array}$ \\
\hline $\begin{array}{l}\mathrm{I}_{1}-\mathrm{Hg}_{1}, \mathrm{Hg}_{2} \\
\mathrm{I}_{1}-\mathrm{Hg}_{3}, \mathrm{Hg}_{6} \\
\mathrm{I}_{2}-\mathrm{Hg}_{3}, \mathrm{Hg}_{4} \\
\mathrm{I}_{2}-\mathrm{Hg}_{1}, \mathrm{Hg}_{5} \\
\mathrm{I}_{3}-\mathrm{Hg}_{3}, \mathrm{Hg}_{6} \\
\mathrm{I}_{3}-\mathrm{Hg}_{2}, \mathrm{Hg}_{4}\end{array}$ & $\begin{array}{l}3.33 \AA \\
3,35 \AA \\
\quad 3.33 \AA \\
\quad \cdot \quad 3.35 \AA \\
3.33 \AA \\
3.35 \AA\end{array}$ & $\begin{array}{l}\mathrm{O}_{1}-\mathrm{O}_{2} \\
\mathrm{O}_{1}-\mathrm{O}_{4}, \mathrm{O}_{5} \\
\mathrm{O}_{1}-\mathrm{O}_{3}, \mathrm{O}_{6} \\
\mathrm{O}_{2}-\mathrm{O}_{3}, \mathrm{O}_{6} \\
\mathrm{O}_{2}-\mathrm{O}_{4}, \mathrm{O}_{5} \\
\mathrm{O}_{3}-\mathrm{O}_{4}\end{array}$ & $\begin{array}{l}3.46 \AA *, 4.06 \AA^{* *} \\
3.77 \AA \\
4.49 \AA \\
3.77 \AA \\
4.49 \AA \\
3.46 \AA *, 4.06 \AA \text { \&* } \\
3.77 \AA\end{array}$ \\
\hline $\begin{array}{l}\mathrm{I}_{1}-\mathrm{O}_{1}, \mathrm{O}_{2} \\
\mathrm{I}_{1}-\mathrm{O}_{3}, \mathrm{O}_{4}, \mathrm{O}_{5}, \mathrm{O}_{6} \\
\mathrm{I}_{2}-\mathrm{O}_{1}, \mathrm{O}_{2}, \mathrm{O}_{5}, \mathrm{O}_{6} \\
\mathrm{I}_{2}-\mathrm{O}_{3}, \mathrm{O}_{4} \\
\mathrm{I}_{3}-\mathrm{O}_{5}, \mathrm{O}_{6}, \mathrm{O}_{3}, \mathrm{O}_{4} \\
\mathrm{I}_{3}-\mathrm{O}_{1}, \mathrm{O}_{2}, \mathrm{O}_{3}, \mathrm{Hg}_{8}, \mathrm{Hg}_{4} \\
\mathrm{Na}_{1}-\mathrm{Hg}_{1}, \mathrm{Hg}_{2}, \mathrm{Hg}_{5}, \mathrm{Hg}_{6} \\
\mathrm{Na}_{2}-\mathrm{Hg}_{3}, \mathrm{Hg}_{4}, \mathrm{Hg}_{5}, \mathrm{Hg}_{6} \\
\mathrm{Na}_{3}-\mathrm{Hg}_{1}, \mathrm{Hg}_{2}, \mathrm{Hg}_{3}\end{array}$ & $\begin{array}{l}3.76 \AA \\
3.92 \AA \\
3.92 \AA \\
3.76 \AA \\
3.76 \AA \\
3.92 \AA \\
3.73 \AA \\
3.73 \AA \\
3.73 \AA\end{array}$ & \multicolumn{2}{|c|}{$\begin{array}{l}* \text { within a chain }-\mathrm{O}-\mathrm{Hg}-\mathrm{O}- \\
\text { ** between two chains }-\mathrm{O}-\mathrm{Hg}-\mathrm{O}--\end{array}$} \\
\hline
\end{tabular}


that had to be corrected for the contributions due to the aluminium reflexions is less than that of those peaks, at low $2 \Theta$ values, which were not affected by these reflexions (Fig. 4). Taking this fact into consideration, it can be concluded that the agreement between calculated and observed intensities is satisfactory, thus showing that the structure should be principally correct also as regards the light atoms.

\section{DESCRIPTION OF THE STRUCTURE}

The following structure is therefore proposed for $\mathrm{Hg}_{2} \mathrm{O}_{2} \mathrm{NaI}$ :

Cell content: $3 \mathrm{Hg}_{2} \mathrm{O}_{2} \mathrm{NaI}$

Space croup: $P 6_{2} 22$ (No. 180)

$6 \mathrm{Hg}$ in $6(f): \frac{1}{2}, 0, \pm z ; \quad 0, \frac{1}{2}, \frac{2}{3} \pm z ; \quad \frac{1}{2}, \frac{1}{2}, \frac{1}{3} \pm z ; \quad z=0.333$

3 I in $3(c): \frac{1}{2}, 0,0 ; 0, \frac{1}{2}, \frac{2}{3} ; \quad \frac{1}{2}, \frac{1}{2}, \frac{1}{8}$

$3 \mathrm{Na}$ in $3(b): 0,0, \frac{1}{2} ; 0,0, \frac{5}{6} ; 0,0, \frac{1}{6}$

$6 \mathrm{O}$ in $6(i): \quad \pm(x, \mathcal{E} x), 0 ; \quad \pm(2 x, x), \frac{2}{3} ; \quad \pm(x, \bar{x}), \frac{1}{3} ; \quad x=0.15$

A fundamental constituent of the structure is the series of infinite planar zig-zag chains - $\mathrm{O}-\mathrm{Hg}-\mathrm{O}-$, lying perpendicularly to the $c$ axis at the heights $z=0, \frac{1}{3}$ and $\frac{2}{3}$ (Fig. 5). The distances $\mathrm{Hg}-\mathrm{O}$ within the chains are $2.03 \AA$ (Table 9 ) and the angles $\mathrm{O}-\mathrm{Hg}-\mathrm{O} 180^{\circ} \pm 3^{\circ}$ and $\mathrm{Hg}-\mathrm{O}-\mathrm{Hg} 110^{\circ} \pm 1^{\circ}$. This $\mathrm{Hg}-\mathrm{O}$ distance and the values of the angles (cf. Refs. ${ }^{14,15}$ ) suggest that the bond between $\mathrm{Hg}$ and $\mathrm{O}$ within the chains is mainly homopolar. Since the interatomic distances are considerably larger between the chains, the forces between them are far weaker.

Each mercury atom is, in addition to the two oxygen atoms at the close distance of $2.03 \AA$, also surrounded by three iodine atoms at the distances $\frac{a}{2}=3.33 \AA$ and $\frac{c}{3}=3.35 \AA$, the two oxygen and the three iodine atoms thus forming a pyramid with the mercury atom in the centre of its base plane (Fig. 5).

Each iodine atom is octaliedrally surrounded by six mercury atoms at the distances 3.33 and $3.35 \AA$. The calculated sum of the ionic radii is $3.26 \AA$ (Ref. ${ }^{16}$ ).

Each sodium atom in the structure is surrounded by four oxygen and four iodine atoms, forming a deformed square Archimedean antiprism. These coordination polyhedra share their base planes to form infinite chains running along the $c$ axis of the unit cell (Fig. 5). The interatomic distances in the polyhedra and between the polyhedra and the chains are listed in Table 9 (Fig. 6). The distances $\mathrm{Na}-\mathrm{I}$ seem to be relatively long but the $\mathrm{Na}-\mathrm{O}$ distances are close to the sum of the ionic radii (Ref. ${ }^{16}$ ):

$$
\begin{array}{llllll} 
& \text { obs. } & \text { calc. } & & \text { obs. } & \text { calc. } \\
\mathrm{Na}-\mathrm{I},(\AA) & \mathbf{3 . 7 3} & \mathbf{3 . 1 1} & \mathrm{Na}-\mathrm{O},(\AA) & 2.41 & \mathbf{2 . 3 \mathrm { C }}
\end{array}
$$

The connection between the chains and the base planes of the Archimedean antiprism is shown clearly in Fig. 7 . 
The author is greatly indebted to Professor A. Ölander for his kind interest in this work and to Dr. A. Magnéli for many valuable discussions. Thanks are also due to Professor J. A. Goedkoop and Dr. A. F. Andresen for very valuable help in the neutron diffraction work. The author wishes to thank Miss Inga-Britt Carlsson and Miss Birgitta Malmros for valuable help in the chemical work and assistance in the calculations. Thanks are also due to the Swedish Board for Computing Machinery for the use of the calculator BESK for a considerable part of the calculating work involved in this investigation. The author is also indebted to G. Blomqvist, S. Westman and S. Assbrink for access to the programs (c.f. Refs.17,18) used for calculations with BESK.

These studies form part of a research program on mercury(II)oxide salts, financially supported by the Swedish Natural Science Research Council.

\section{REFERENCES}

1. Aurivillius, K. Acta Chem. Scand. 10 (1956) 852.

2. Aurivillius, K. and Carlsson, I.-B. Acta Chem. Scand. 12 (1958) 1297.

3. Laruelle, M. P. Compt. rend. 241 (1955) 802.

4. Charlot, G. and Bézier, D. Quantitative Inorganic Analysis, 3rd ed. London, New York 1957, p. 486.

5. Barnes, R. B., Richardson, D., Berry, J. W. and Wood, R. L. Ind. Eng. Chem. Anal. Ed. 17 (1945) 605.

6. Kolthoff, I. M. and Sandell, E. B. Textbook of Quantitative Inorganic Analysis, 3rd ed. New York 1952, p. 599.

7. Kolthoff, I. M. and Sandell, E. B. Textbook of Quantitative Inorganic Analysis, 3rd ed. New York 1952, p. 717.

8. Hambling, P. G. Acta Cryst. 6 (1953) 98.

9. The abstract "Pulverfotogram" published at the Institute of Chemistry, University of Uppsala, Uppsala, Sweden; Berger, S. Acta Chem. Scand. 7 (1953) 612; Heller, E. Z. Krist. 106 (1954) 122.

10. International Tables for X-ray Crystallography, Vol. 1, Birmingham 1952.

11. Bacon, G. E. Neutron Diffraction, Oxford 1955, p. 28.

12. Bacon, G. E. Neutron Diffraction, Oxford 1955, p. 89.

13. Booth, A. D. Fourier Technique in X-ray Organic Structure Analysis, Cambridge 1948 , p. 101.

14. Wells, A. F. Structural Inorganic Chemistry, Oxford 1950, p. 58.

15. Aurivillius, K. Acta Chem. Scand. 4 (1950) 1413.

16. Wells, A. F. Structural Inorganic Chemistry, Oxford 1950, p. 70.

17. Westman, S., Blomqvist, G. and Asbrink, S. Arkiv Kemi 14 (1959) 535

18. Assbrink, S., Blomqvist, G. and Westman, S. Arkiv Kemi 14 (1959) 545.

Received May 16, 1960. 